\title{
Pericardial Drainage by Xyphoidian Route at the Chu Point G
}

\author{
Mamadou Diakité1,2*, Abdoulaye Kanté2,3, Bréhima Coulibaly2,3, Mamadou Almamy Keita3, \\ Mariam Daou ${ }^{2}$, Demba Yattera ${ }^{3}$, Samba Sidibe1,2, Souleymane Coulibaly ${ }^{1}$, Boureima Dembele ${ }^{1}$, \\ Alou Sangaré1, Boureima Dembele1, Mariam Sacko1,2, Nouhoun Diallo', Ilo Bella Diall1,2 \\ ${ }^{1}$ Cardiology Department, University Hospital Center (CHU) Point G, Bamako, Mali \\ ${ }^{2}$ Faculty of Medicine of Odonto-Stomatology (FMOS), Bamako, Mali \\ ${ }^{3}$ Department of Surgery B, University Hospital Center (CHU) Point G, Mali \\ Email: *diakitemamadoua@yahoo.fr
}

How to cite this paper: Diakité, M., Kanté, A., Coulibaly, B., Keita, M.A., Daou, M., Yattera, D., Sidibe, S., Coulibaly, S., Dembele, B., Sangaré, A., Dembele, B., Sacko, M., Diallo, N. and Diall, I.B. (2021) Pericardial Drainage by Xyphoidian Route at the Chu Point G. Open Journal of Thoracic Surgery, $11,11-17$.

https://doi.org/10.4236/ojts.2021.111002

Received: October 27, 2020

Accepted: December 23, 2020

Published: March 10, 2021

Copyright $\odot 2021$ by author(s) and Scientific Research Publishing Inc. This work is licensed under the Creative Commons Attribution International License (CC BY 4.0).

http://creativecommons.org/licenses/by/4.0/ (c) (i) Open Access

\begin{abstract}
Tuberculosis is a public health problem in Mali. Pulmonary localization is the most frequent and extra-pulmonary involvement, in particular serous, is possible. In this study, we analyze our results of surgical pericardial drainage in tuberculous pericarditis. Methodology: We carried out a retrospective study at the CHU Point G over a period of five years from January 2012 to December 2017. The histological examination carried out on all the surgical specimens made it possible to retain the diagnosis of tuberculous pericarditis. Results: We identified and operated on 49 cases of tuberculous pericarditis, i.e. $70 \%$ of the pericardial drainage performed during the same period. The average age was 31.5 years ( 28 men and 21 women). The most common clinical signs were dyspnea (61.2\%), chest pain (26.6\%) and fever (12.2\%). Pericardial drainage with pericardial biopsy was performed by xiphoid route in all of our patients. The mortality and morbidity rates were $4.1 \%$ and $8.2 \%$, respectively. Conclusion: Pericardial tuberculosis attacks are frequent in Mali. The etiological diagnosis is based on the histology of the pericardial biopsy which can only be obtained surgically.
\end{abstract}

\section{Keywords}

Tuberculous Pericarditis, Pericardial Biopsy, Surgical Drainage

\section{Introduction}

Tuberculosis is still a public health problem, particularly in our countries south of the Sahara with the co-infection of HIV [1]. Its pulmonary localization remains by far the most frequent. However, extra-pulmonary, especially serous, 
attacks are possible. It is most often tuberculous pericarditis, which can lead to fatal complications [2] [3]. It can occur at any age but mainly affects the young subject. The objective of this study was to analyze the outcome of pericardial drainage of tuberculous pericarditis in the surgery department of the Point $G$ University Hospital Center.

\section{Materials and Methods}

We carried out a retrospective study from January 2012 to December 2017 in the B surgery department at the Point G University Hospital in Bamako. All patients operated on for pericarditis were included in whom histological examination confirmed the diagnosis of tuberculosis by the demonstration of pericardial granulomatous inflammation (Figure 1(A) and Figure 1(B)). Patients operated on for non-tuberculous pericarditis were not included in this study. Sputum examination for acid-fast bacilli (AFB) was performed in all patients with chronic cough with sputum. A complete clinical examination, cardiac ultrasound, ECG and preoperative laboratory workup were performed in all patients. The parameters studied were recited in the patient files and in the operating report books. They included: 1) socio-demographic data, o clinical and paraclinical signs, 2) the treatments, 3) postoperative treatment. All patients received quadruple therapy for tuberculosis after surgery.

The data were entered and analyzed using the Epi Info software (version 6). The $\mathrm{X}^{2}$ and Student test were used to compare our results with those of other authors. The significance level was set at 0.05 .

\section{Results}

During the 5-year study, 49 patients were surgically drained in surgical department, i.e. $70 \%$ of pericardial drainages; $1.6 \%$ of surgeries and $34.7 \%$ of open heart cardiology procedures during the study period.

The average age was 31.5 years with extremes of 2 years and 84 years. Among these cases, $79.6 \%$ of the patients were under 40 years old. These were 28 men and 21 women, 32 patients resided in Bamako, 16 came from 8 regions and 1 outside Mali (1 Guinean).

Among the circumstances of discovery, 30 patients consulted for dyspnea (61.2\%); 13 patients for chest pain (26.6\%), and 6 for fever (12.2\%). A notion of tuberculosis contagion was found in thirty-three patients, i.e. $67.3 \%$. A history of
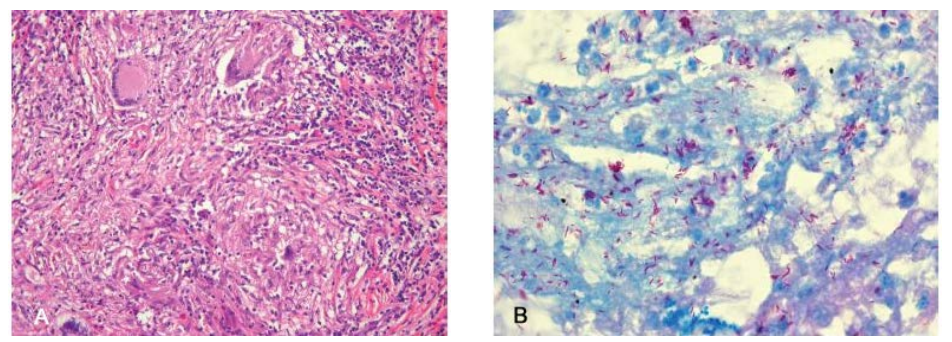

Figure 1. (A) Tuberculosis case follicular lesions; (B) Tubercular follicular lesion. 
pulmonary tuberculosis was found in 6 patients and 2 patients were seropositive. Pericardial friction was found in $75.5 \%$ of our patients.

We found on cardiac ultrasound performed in all patients a pericardial effusion of moderate abundance in $18.4 \%$ and of high abundance with signs of compression in $81.6 \%$ (Figure 2).

The ECG performed in all patients showed sinus tachycardia in $95.9 \%$ associated with microvoltage and diffuse repolarization disorders in $55.1 \%$ (Figure 3).

We noted on the $\mathrm{x}$-ray the image of a carafe heart in $85.7 \%$ (Figure 4).

Pericardial biopsy confirmed the diagnosis of tuberculosis in all patients with evidence of pericardial granulomatous inflammation (Figure 1).

Seven patients presented with Microscopy-positive Pulmonary Tuberculosis (TPM+), four others with Microscopy-negative Pulmonary Tuberculosis (TPM-).

$87.7 \%$ of patients $(n=43)$ were operated on urgently due to hemodynamic instability and/or symptoms of poor clinical tolerance.

Local anesthesia with $2 \%$ xylocaine without preservative by progressive infiltration of the xiphoid region in the presence of the anesthesiologist in the operating room was carried out in $93.9 \%$. In $6.1 \%$ it was associated with general anesthesia.

Pericardial drainage by pericardotomy with pericardial biopsy was performed by the xiphoid route in all our patients (Figure 5). It returned between 2250 and $1600 \mathrm{cc}$ of citrus yellow fluid in $81.6 \%$ of patients and in $18.4 \%$ of purulent fluid.

Four patients presented a postoperative complication (morbidity $=8.2 \%$ ): Two recurrences and two infections of the surgical site (Table 1).

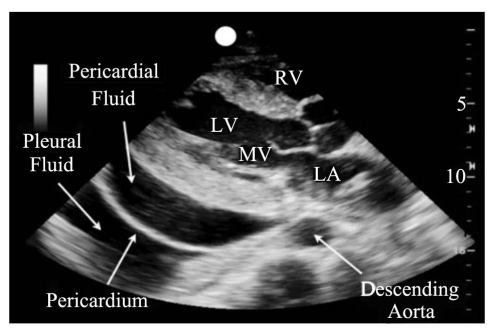

Figure 2. Cardiac ultrasound showing pericardial effusion with ultrasound signs of tamponade.

Table 1. Distribution of patients according to morbidity and mortality after surgical drainage.

\begin{tabular}{cc}
\hline Short-term outcomes & $\mathrm{N}^{\bullet}$ Patients \\
\hline Mortality & $\mathbf{2 ( 4 . 1 \% )}$ \\
Intraoperative cardiac arrest & 1 \\
Septic shock & 1 \\
Morbidity & $\mathbf{2 ( 8 . 2 \% )}$ \\
recurrence & 2 \\
Surgical site infection & 2 \\
\hline
\end{tabular}




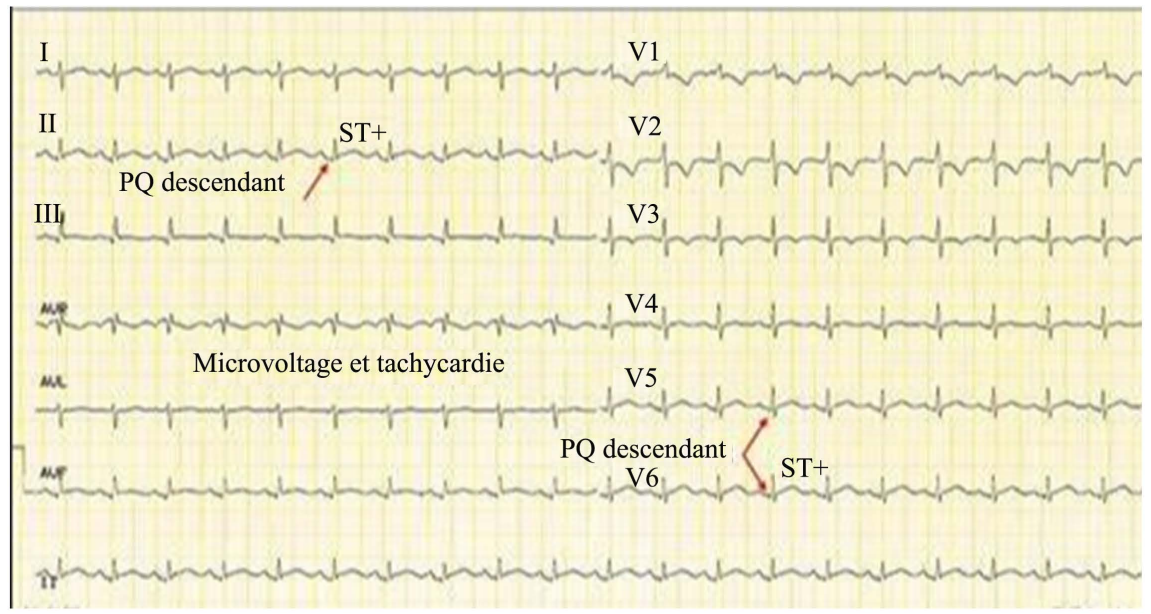

Figure 3. ECG showing microvoltage and tachycardia.

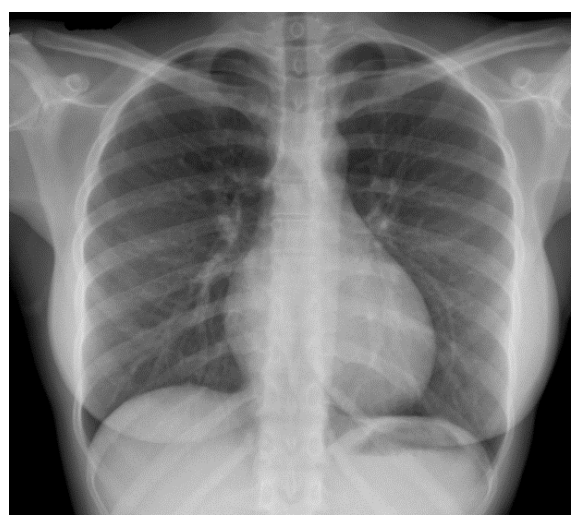

Figure 4. AP chest $\mathrm{x}$-ray showing large pericardial effusion.

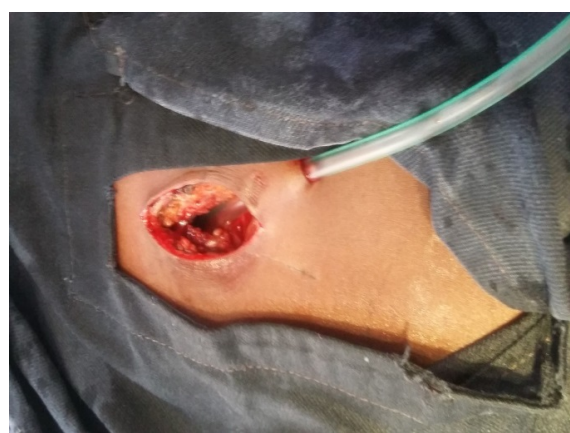

Figure 5. Xiphoid pericardial drainage.

Two patients died (mortality $=4.1 \%$ ): one from electromechanical dissociation during surgery and another from a lasting state of septic shock.

The patients received a quadruple combination for 2 months of: pyrazinamide (Piriléne) $30 \mathrm{mg} / \mathrm{Kg} / \mathrm{D}$; isionazide (Rimifon) at $5 \mathrm{mg} / \mathrm{Kg} / \mathrm{D}$ ethambutol (Dexambutol) $20 \mathrm{mg} / \mathrm{Kg} / \mathrm{D}$ and rifampicin (Rifadine) $10 \mathrm{mg} / \mathrm{kg} / \mathrm{D}$.

After 2 months of quadruple treatment pyrazinamide and ethambutol were stopped and treatment was continued for 4 months with dual therapy combining isionazide and rifampicin with usual hepatic and ocular monitoring. 


\section{Discussion}

Tuberculosis is still a frequent and serious pathology. Its extra-pulmonary localization in the general population is of the order of $15 \%$ [4]. Cardiac complications are possible, but pericardial involvement is by far the most common [5]. About 1 to $8 \%$ prevalence in the general literature according to Sida-Diaz [1]; in developing countries like ours, tuberculosis is the leading cause of pericarditis [6]. This prevalence could reach $65 \%$ in the HIV field [1] [5]. A study by Lepori [7] has shown an increase in cases of pericarditis in Africa, in relation to that of AIDS cases [7]. Tuberculous pericarditis mainly affects young subjects under the age of 40 (79.6\% in our study); which is consistent with the data in the literature [5] [6]. The diagnostic suspicion of tuberculous pericarditis should be clinical in front of classic signs known as tuberculous impregnation associated with a very often dry chronic cough, precordial chest pain and pericardial effusion syndrome. Indeed, it is characterized by the abundance of pericardial effusion, often circumferential, which can quickly be life-threatening by tamponade [8] [9]. A South African study on the epidemiology of pericardial effusions had shown that in $69.5 \%$ of cases, the effusions of great abundance were of tuberculous origin [5]. Two-dimensional echocardiography remains essential for a positive diagnosis because the clinical picture can be insidious with an inaugural tamponade [1] [3] [10].

However, the etiological diagnosis is often problematic [11]. In our study, pericardial biopsy during pericardial drainage allowed us to avoid this problem, which is why we believe that surgical drainage should always be performed to perform the biopsy simultaneously.

Furthermore, it seems that effusions from tuberculous pericarditis should be drained because of their abundance and rapid reconstitution [8], repeated punctures being a source of secondary infections.

The prognosis depends on the speed of the diagnosis. Indeed we must always fear chronic constrictive pericarditis. Imazio [12] reported in a study of a cohort of 500 cases of pericarditis a rate of constriction of 31.65 per 1000 for tuberculous pericarditis. This rate can reach 52.74 per 1000 when they become purulent.

The surgical management of pericarditis is now well codified.

S. Mianfoutila et al. [8] in a series of 10 drainages with biopsies performed a left anterolateral thoracotomy at the level of the 4th and 5th intercostal spaces. Our preference was the xiphoid route because of its precision and less aggressiveness. Pericarditis surgery is life-saving heart surgery. The clinical improvement is immediate and constant. The procedure makes it possible to completely evacuate the pericardial cavity, to assess the state of the heart, the macroscopic aspect of the pericardium and to perform the pericardial biopsy, the only way to provide the aetiological diagnosis on which the treatment depends.

The favorable outcome with aetiological treatment is mentioned in the literature [8] but some complications have been reported. We recorded 2 deaths (4.1\%) of which 1 case occurred in the operating room and 1 case in an HIV-positive 
patient. The morbidity rate was $8.2 \%$. These were two cases of recurrence and two cases of surgical site infections.

\section{Conclusions}

Pericardial tuberculosis attacks are frequent in Mali. If echocardiography is essential to establish the diagnosis and the seriousness, the aetiological diagnosis is based on the histology of the pericardial biopsy which can only be obtained surgically.

Pericardial drainage in our work setting should be systematic because of the rapid replenishment of the effusion. Particular interest should be given to screening in urban areas, but above all in rural areas, for early and adequate treatment in young subjects.

\section{Authors' Contribution}

All of the authors contributed to this work. They read and approved the final version of the manuscript.

\section{Conflicts of Interest}

The authors declare no conflict of interest.

\section{References}

[1] Sida-Díaz, J., Nuñez-Fragoso, J.C., Martínez-Burciaga, J., Valles-Guerrero, A., et al. (2011) Tuberculous Pericarditis. A Case Reported and a Brief Review. Rev Med Inst Mex Seguro Soc., 49, 75-78.

[2] Light, R.W. (2011) Pleural Effusions. Medical Clinics of North America, 95, 1055-1070. https://doi.org/10.1016/j.mcna.2011.08.005

[3] Gupta, N.K., Agrawal, R.K., Srivastav, A.B. and Ved, M.L. (2011) Echocardiographic Evaluation of Heart in Chronic Obstructive Pulmonary Disease Patient and Its Co-Relation with the Severity of Disease. Lung India, 28, 105-109. https://doi.org/10.4103/0970-2113.80321

[4] Centers for Disease Control (CDC) (1982) Tuberculosis: United States. MMWR Morbidity and Mortality Weekly Report, 32, 443-446.

[5] Reuter, H., Burgess, L.J. and Doubell, A.F. (2005) Epidemiology of Pericardial Effusions at a Large Academic Hospital in South Africa. Epidemiology \& Infection, 133, 393-399. https://doi.org/10.1017/S0950268804003577

[6] Bouakez-Ajabi, A., Bouakez, H. and Zaouali, R.M. (1999) Pericarditis: Clinical and Etiological Aspects. Maghreb Medicine, 78, 29-31.

[7] Lepori, M., Tinguely, F., Erard, V., Delabays, A. and Nicod, P. (1999) Pericardial Involvement in Patients Infected with Human Immunodeficiency Virus (HIV). Schweizerische Medizinische Wochenschrift, 129, 736-740.

[8] Mianfoutila, S., Nkiwabonga, L. and Nkoua, J.L. (1996) Surgical Drainage of the Pericardium. About 10 Cases. Medicine from Black Africa, 43, 8-9.

[9] Fatimi, S.H., Faheem-ul-Haq, Jalil, F., Muzaffar, M. and Hanif, H.M. (2011) Tuberculous Pericardial Abscess with Impending Pericardial Effusion and Cardiac Tamponade. Journal Of Pakistan Medical Association, 61, 286-287. 
[10] Heller, T., Lessells, R.J., Wallrauch, C. and Brunetti, E. (2010) Tuberculosis Pericarditis with Cardiac Tamponade: Management in the Resource-Limited Setting. American Society of Tropical Medicine and Hygiene, 83, 1311-1314. https://doi.org/10.4269/ajtmh.2010.10-0271

[11] Sia, I.G. and Wieland, M.L. (2011) Current Concepts in the Management of Tuberculosis. Mayo Clinic Proceedings, 86, 348-361.

https://doi.org/10.4065/mcp.2010.0820

[12] Imazio, M., Brucato, A., Maestroni, S., Cumetti, D., Belli, R., Trinchero, R. and Adler, Y. (2011) Risk of Constrictive Pericarditis after Acute Pericarditis. Circulation, 11, 1270-1275. https://doi.org/10.1161/CIRCULATIONAHA.111.018580 